\title{
Coulisses
}

Revue de théâtre

25 | Hiver 2002

Varia

\section{Combler les manques, amplifier les actions en cours}

Entretien avec l'Adjoint à la culture de Besançon, Michel Roignot. Propos recueillis par Lucile Garbagnati, décembre 2001

\section{Lucile Garbagnati}

\section{CpenEdition}

\section{Journals}

Édition électronique

URL : http://journals.openedition.org/coulisses/5893

DOI : $10.4000 /$ coulisses.5893

ISSN : 2546-9460

Éditeur

Presses universitaires de Franche-Comté

\section{Édition imprimée}

Date de publication : 1 janvier 2002

Pagination : 6-8

ISBN : 2-84627-052-X

ISSN : $1150-594 X$

Référence électronique

Lucile Garbagnati, «Combler les manques, amplifier les actions en cours », Coulisses [En ligne], 25 |

Hiver 2002, mis en ligne le 24 octobre 2019, consulté le 21 décembre 2020. URL : http://

journals.openedition.org/coulisses/5893; DOI : https://doi.org/10.4000/coulisses.5893

Ce document a été généré automatiquement le 21 décembre 2020.

Coulisses 


\section{Combler les manques, amplifier les actions en cours}

Entretien avec l'Adjoint à la culture de Besançon, Michel Roignot. Propos recueillis par Lucile Garbagnati, décembre 2001

\section{Lucile Garbagnati}

Michel Roignot, depuis les élections a remplacé Marcel Ferréol à la Culture. Il a semblé intéressant à Coulisses de lui demander quelles grandes orientations de la politique culturelle de la ville étaient envisagées. D'autant plus que la Mairie a toujours soutenu, à des hauteurs variables, les projets du T.U.F.C.

COULISSES, (c.): APRÈS LES Élections, COMMENT SE RÉPARTISSENT LES FONCTIONS ? Pourquoi avez-vous été délégué à la culture, alors que dans l'équipe municipale précédente vous aviez en charge le patrimoine?

Michel Roignot (M.R.) : Les tâches se sont réparties en fonction des souhaits et des compétences. Il se trouve que je me suis toujours intéressé à la musique. À titre personnel, j'ai fait partie du chœur Schultz, soutenu l'opéra-théâtre dans son programme de promotion des jeunes chanteurs d'opéra. J'aime beaucoup le lyrique, et de façon plus général le spectacle vivant. Toutefois, dans cette fonction ce ne sont pas les goûts personnels qui comptent, c'est une vision d'ensemble pour combler les manques, amplifier les actions en cours. Depuis un peu plus de six mois que j'observe la vie culturelle bisontine, ce qui frappe c'est le manque total dans le domaine de l'art plastique. Nous avons beaucoup d'artistes, dont certains sont renommés, mais il n'y a rien où ils puissent montrer leur travail. Il s'agira donc de créer un lieu et une programmation ad hoc. Dans le domaine musical il faudra donner toute sa place à la musique actuelle contemporaine. Pour le théâtre et le lyrique, il s'agit d'amplifier ce qui existe déjà.

\section{C. : QUE VA DEVENIR LE FESTIVAL de MUSIQUE ?}

M.R. : Il pose énormément de problèmes. La diffusion de masse des œuvres par les moyens multimédia, la prolifération des festivals de musique exige que l'on s'interroge sur la spécificité, l'originalité d'une telle manifestation au vu de son coût. Faut-il garder l'idée d'un festival d'orchestre? Faut-il même maintenir le concours 
des jeunes chefs d'orchestre? Dans quelle mesure influe-t-il sur la carrière des lauréats? Faut-il intégrer les musiques actuelles ? Comment? quelle relation avec les groupes locaux? Ces questions sont à l'étude afin de trouver une solution satisfaisante.

\section{C. : QUEL AVENIR ENVISAgEZ-VOUS POUR LES RENCONTRES JEUNE CRÉATION (R.J.C.) ?}

M.R. : C'est une opération à maintenir. J'envisage toutefois de lui donner deux inflexions : accorder une plus grande place au théâtre de rue, repérer une ou deux troupes plus prometteuses de manière à pouvoir leur accorder par la suite un soutien pour approfondir leur travail. Évidemment cela ne peut se faire qu'avec le partenariat du C.D.N et de la Scène nationale.

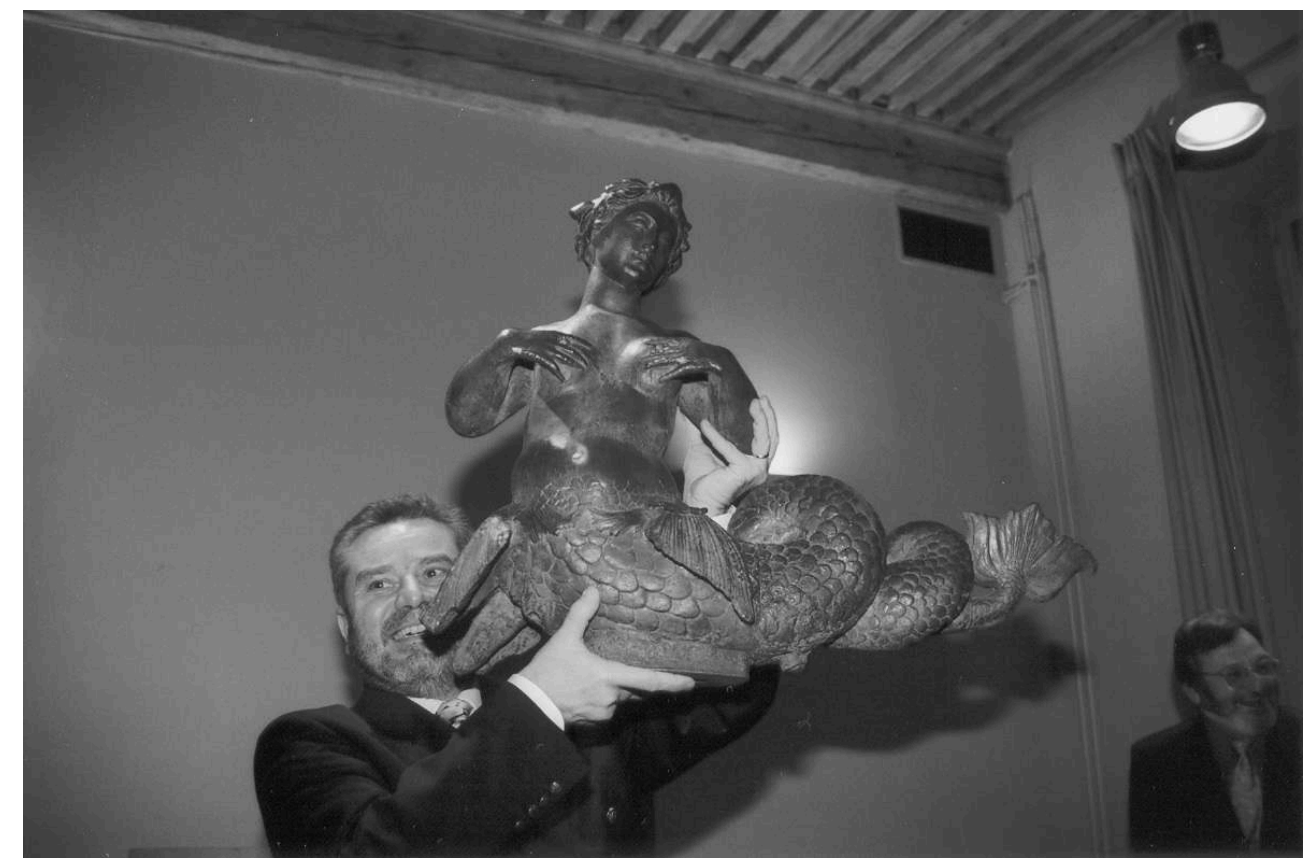

Photo Georges Pannetton

\section{C. : ENVISAgEZ-VOUS UN CONCOURS ENTRE LES JEUNES COMPAgNIES ?}

M.R. : Absolument pas. Beaucoup de troupes ne vivent que pour les R.J.C espérant s'y faire remarquer. Elles demandent des subventions et se nourrissent d'illusions. Au moins, la règle du jeu sera claire. En tous cas, cela permettra de donner sa chance à l'une ou deux d'entre elles. Nous voudrions également rendre la manifestation pluridisciplinaire, comme elle le fut au début, lorsqu'elle s'appelait Besançon Ville Ouverte aux Jeunes, tout en gardant l'accent sur le théâtre.

\section{C. : MICHEL DUBOIS VA QUITTER SES FONCTIONS DE DIRECTEUR DU C.D.N. LA VILLE EST-ELLE IMPLIQUÉE DANS LE CHOIX DE SON SUCCESSEUR?}

M.R. : La décision revient au ministère de l'Éducation et de la Culture, mais la région et la ville sont associées à la procédure du choix du futur directeur. C'est le ministère qui lance la procédure de l'appel à candidatures. Il envoie la liste des candidats aux collectivités en janvier, de manière à ce que le nouveau directeur soit désigné fin mars. Il peut ainsi organiser la saison suivante. L'audition se déroule devant les représentants de ces institutions qui envoient un avis classé. Le ministère en tient compte dans sa décision. 


\section{C. : QUELS ONT LES CRITÈRES RETENUS ?}

M.R. : Il ne faut pas oublier qu'un C.D.N. a une mission de création. Dans la logique de monstration du contemporain qui anime la ville, nous mettons en avant la création contemporaine. Nous souhaitons également accorder une place à des échanges internationaux en invitant une troupe étrangère.

C. : Qu'en eSt-IL de LA DiRection du théâtre de L'espace, qui pour citer sa plaquette en est à Godot comme directeur?

M.R. : Au premier trimestre 2002, il doit y avoir, de façon réglementaire, une mission d'inspection du ministère, les Scènes nationales étant financées à $50 \%$ par l'état et à $50 \%$ par les collectivités. Ce sera l'occasion de revoir la question des financements. De toutes façons, c'est l'État qui lance la procédure de recrutement sur des critères qualitatifs de programmation puisque contrairement à un C.D.N., une Scène nationale n'a pas de mission de création mais de diffusion.

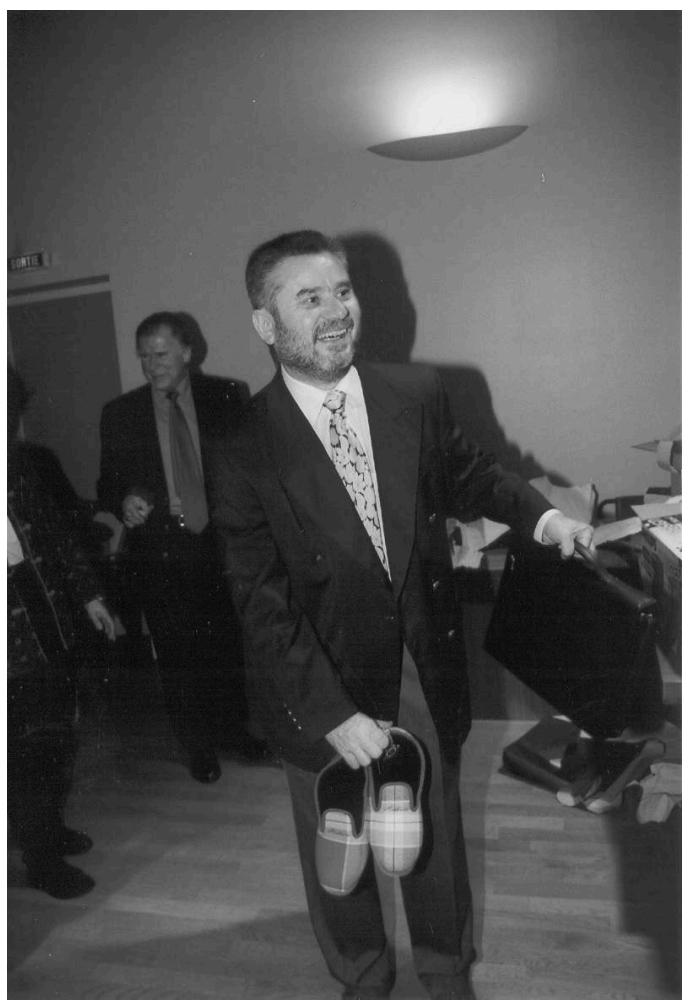

Photo Georges Pannetton

\section{C. : QUEL EST VOTRE RAPPORT AVEC LE THÉÂTRE BACCHUS ?}

M.R. : Le Conseil Général a créé les «scènes départementales » sans concertation. Quand on ajoute une reconnaissance à une structure privée, il y a lieu de nous contacter.

\section{C. : ET LE PETIT THÉÂTRE DE LA BOULOIE ?}

M.R. : Le Petit Théâtre de La Bouloie est propriété du C.R.O.U.S. La ville n'a pas son mot à dire ès/qualités. De plus, les responsables ne sont pas venus me voir.

\section{C. : QUE VA DEVENIR LE MONTJOYE ?}

M.R. : Il sera démoli. En effet, la salle est complètement hors-norme et la remettre en état exige des travaux qui reviendraient aussi chers que de construire du neuf dans un endroit où il n'y aura pas de nuisance pour les riverains. 


\section{C. : QUELLE EST VOTRE POSITION VIS-À-VIS DU THÉÂTRE AMATEUR ?}

M.R. : Il existe un véritable fourmillement de groupes, proposant des projets souvent de valeur, dirigés par des gens passionnés. La ville ne peut aider tout le monde, surtout en période de restrictions budgétaires, pour le moment, je n'ai pas de réponse.

C. : PENSEZ-VOUS METTRE EN PLACE UNE STRUCTURE QUI RENDRAIT LeS MÊMES SERVICES QUE L'ANCIEN CENTRE De RENCONTRES, QUI PRENDRAIT EN CHARge LA FORMATION DES AMATEURS, QUEL QUE SOIT LEUR NIVEAU ?

M.R.: Pour le moment, je n'ai pas d'opinion. Le paysage théâtral bisontin est extrêmement complexe. Des petites compagnies, issues des théâtres amateurs et des formations universitaires, naissent tous les jours. Il faut réfléchir à la question. 